\title{
ITERATIVE METHODS FOR SOLVING FIXED-POINT PROBLEMS WITH NONSELF-MAPPINGS IN BANACH SPACES
}

\author{
YAKOV ALBER, SIMEON REICH, AND JEN-CHIH YAO
}

Received 21 January 2002

We study descent-like approximation methods and proximal methods of the retraction type for solving fixed-point problems with nonself-mappings in Hilbert and Banach spaces. We prove strong and weak convergences for weakly contractive and nonexpansive maps, respectively. We also establish the stability of these methods with respect to perturbations of the operators and the constraint sets.

\section{Preliminaries}

Let $B$ be a real uniformly convex and uniformly smooth Banach space [12] with norm $\|\cdot\|$, let $B^{*}$ be its dual space with the dual norm $\|\cdot\|_{*}$ and, as usual, denote the duality pairing of $B$ and $B^{*}$ by $\langle x, \varphi\rangle$, where $x \in B$ and $\varphi \in B^{*}$ (in other words, $\langle x, \varphi\rangle$ is the value of $\varphi$ at $x$ ).

We recall that the uniform convexity of the space $B$ means that, for any given $\epsilon>0$, there exists $\delta>0$ such that for all $x, y \in B$ with $\|x\| \leq 1,\|y\| \leq 1$, and $\|x-y\|=\epsilon$, the inequality

$$
\|x+y\| \leq 2(1-\delta)
$$

holds. The function

$$
\delta_{B}(\epsilon)=\inf \left\{1-2^{-1}\|x+y\|:\|x\|=1,\|y\|=1,\|x-y\|=\epsilon\right\}
$$

is called the modulus of convexity of the space $B$.

The uniform smoothness of the space $B$ means that, for any given $\epsilon>0$, there exists $\delta>0$ such that the inequality

$$
2^{-1}(\|x+y\|+\|x-y\|)-1 \leq \epsilon\|y\|
$$

Copyright (C) 2003 Hindawi Publishing Corporation Abstract and Applied Analysis 2003:4 (2003) 193-216 2000 Mathematics Subject Classification: 47H06, 47H09, 47H10, 47H14, 49M25

URL: http://dx.doi.org/10.1155/S1085337503203018 
holds for all $x, y \in B$ with $\|x\|=1$ and $\|y\| \leq \delta$. The function

$$
\rho_{B}(\tau)=\sup \left\{2^{-1}(\|x+y\|+\|x-y\|)-1:\|x\|=1,\|y\|=\tau\right\}
$$

is called the modulus of smoothness of the space $B$.

We observe that the space $B$ is uniformly convex if and only if

$$
\delta_{B}(\epsilon)>0 \quad \forall \epsilon>0,
$$

and that it is uniformly smooth if and only if

$$
\lim _{\tau \rightarrow 0} h_{B}(\tau)=\lim _{\tau \rightarrow 0} \frac{\rho_{B}(\tau)}{\tau}=0
$$

Recall that the nonlinear, in general, operator $J: B \rightarrow B^{*}$ defined by

$$
\|J x\|_{*}=\|x\|, \quad\langle x, J x\rangle=\|x\|^{2}
$$

is called the normalized duality mapping.

The following estimates, established in $[2,3]$, will be used in the proofs of the convergence and stability theorems below (e.g., Theorems 3.2 and 4.9). Define $C(s, t): \mathbb{R}^{+} \times \mathbb{R}^{+} \rightarrow \mathbb{R}^{+}$by

$$
C(s, t)=\sqrt{\frac{s^{2}+t^{2}}{2}} .
$$

If $B$ is a uniformly smooth Banach space, then for all $x, y \in B$,

$$
\langle x-y, J x-J y\rangle \leq 2 C^{2}(\|x\|,\|y\|) \rho_{B}\left(\frac{4\|y-x\|}{C(\|x\|,\|y\|)}\right)
$$

and if $B$ is a uniformly convex Banach space, then for all $x, y \in B$,

$$
\langle x-y, J x-J y\rangle \geq 8 C^{2}(\|x\|,\|y\|) \delta_{B}\left(\frac{\|y-x\|}{C(\|x\|,\|y\|)}\right) .
$$


If $\|x\| \leq R$ and $\|y\| \leq R$, then, respectively,

$$
\begin{aligned}
& \langle x-y, J x-J y\rangle \leq 2 L R^{2} \rho_{B}\left(\frac{4\|y-x\|}{R}\right), \\
& \langle x-y, J x-J y\rangle \geq(2 L)^{-1} R^{2} \delta_{B}\left(\frac{\|y-x\|}{2 R}\right),
\end{aligned}
$$

where $1<L<1.7$ is the Figiel constant $[10,17]$. Furthermore, in a uniformly smooth Banach space, we also have for all $x, y \in B$,

$$
\|J x-J y\|_{*} \leq 8 R h_{B}\left(16 L R^{-1}\|x-y\|\right) .
$$

Now we recall the definitions of nonexpansive and weakly contractive mappings (see, e.g., $[4,6,11])$.

Definition 1.1. A mapping $A: G \rightarrow B$ is said to be nonexpansive on the closed convex subset $G$ of a Banach space $B$ if for all $x, y \in G$,

$$
\|A x-A y\| \leq\|x-y\| .
$$

Definition 1.2. A mapping $A$ is said to be weakly contractive of class $C_{\psi(t)}$ on a closed convex subset $G$ of a Banach space $B$ if there exists a continuous and increasing function $\psi(t)$ defined on $\mathbb{R}^{+}$such that $\psi$ is positive on $\mathbb{R}^{+} \backslash\{0\}$, $\psi(0)=0, \lim _{t \rightarrow+\infty} \psi(t)=+\infty$, and for all $x, y \in G$,

$$
\|A x-A y\| \leq\|x-y\|-\psi(\|x-y\|)
$$

We also use the concept of a sunny nonexpansive retraction $[9,11,13]$.

Definition 1.3. Let $G$ be a nonempty closed convex subset of $B$. A mapping $Q_{G}$ : $B \rightarrow G$ is said to be

(i) a retraction onto $G$ if $Q_{G}^{2}=Q_{G}$;

(ii) a nonexpansive retraction if it also satisfies the inequality

$$
\left\|Q_{G} x-Q_{G} y\right\| \leq\|x-y\| \quad \forall x, y \in B
$$

(iii) a sunny retraction if for all $x \in B$ and for all $0 \leq t<\infty$,

$$
Q_{G}\left(Q_{G} x+t\left(x-Q_{G} x\right)\right)=Q_{G} x
$$

Proposition 1.4. Let $G$ be a nonempty closed convex subset of $B$. A mapping $Q_{G}: B \rightarrow G$ is a sunny nonexpansive retraction if and only if for all $x \in B$ and for all $\xi \in G$,

$$
\left\langle x-Q_{G} x, J\left(Q_{G} x-\xi\right)\right\rangle \geq 0 .
$$


196 Iterative methods

More information regarding sunny nonexpansive retractions can be found in $[11,16]$.

\section{Recursive inequalities}

We will often use the following facts concerning numerical recursive inequalities (see $[5,7,8])$.

LEMMA 2.1. Let $\left\{\lambda_{k}\right\}$ be a sequence of nonnegative numbers and $\left\{\alpha_{k}\right\}$ a sequence of positive numbers such that

$$
\sum_{0}^{\infty} \alpha_{n}=\infty
$$

Let the recursive inequality

$$
\lambda_{n+1} \leq \lambda_{n}-\alpha_{n} \psi\left(\lambda_{n}\right), \quad n=0,1,2, \ldots
$$

hold, where $\psi(\lambda)$ is a continuous strictly increasing function for all $\lambda \geq 0$ with $\psi(0)=0$. Then

(1) $\lambda_{n} \rightarrow 0$ as $n \rightarrow \infty$;

(2) the estimate of convergence rate

$$
\lambda_{n} \leq \Phi^{-1}\left(\Phi\left(\lambda_{0}\right)-\sum_{0}^{n-1} \alpha_{j}\right)
$$

is satisfied, where $\Phi$ is defined by the formula $\Phi(t)=\int d t / \psi(t)$ and $\Phi^{-1}$ is its inverse function.

LemmA 2.2. Let $\left\{\lambda_{k}\right\}$ and $\left\{\gamma_{k}\right\}$ be sequences of nonnegative numbers and $\left\{\alpha_{k}\right\} a$ sequence of positive numbers satisfying conditions (2.1) and

$$
\frac{\gamma_{n}}{\alpha_{n}} \longrightarrow 0 \quad \text { as } n \longrightarrow \infty
$$

Let the recursive inequality

$$
\lambda_{n+1} \leq \lambda_{n}-\alpha_{n} \psi\left(\lambda_{n}\right)+\gamma_{n}, \quad n=0,1,2, \ldots, \lambda_{0}=\bar{\lambda}
$$

be given, where $\psi(\lambda)$ is a continuous strictly increasing function for all $\lambda \geq 0$ with $\psi(0)=0$. Then

(1) $\lambda_{n} \rightarrow 0$ as $n \rightarrow \infty$; 
(2) there exists a subsequence $\left\{\lambda_{n_{l}}\right\} \subset\left\{\lambda_{n}\right\}, l=1,2, \ldots$, such that

$$
\begin{aligned}
\lambda_{n_{l}} & \leq \psi^{-1}\left(\frac{1}{\sum_{0}^{n_{l}} \alpha_{m}}+\frac{\gamma_{n_{l}}}{\alpha_{n_{l}}}\right), \\
\lambda_{n_{l}+1} & \leq \psi^{-1}\left(\frac{1}{\sum_{0}^{n_{l}} \alpha_{m}}+\frac{\gamma_{n_{l}}}{\alpha_{n_{l}}}\right)+\gamma_{n_{l}}, \\
\lambda_{n} & \leq \lambda_{n_{l}+1}-\sum_{n_{l}+1}^{n-1} \frac{\alpha_{m}}{\mathscr{A}_{m}}, \quad n_{l}+1<n<n_{l+1}, \mathscr{A}_{m}=\sum_{0}^{m} \alpha_{i}, \\
\lambda_{n+1} & \leq \bar{\lambda}-\sum_{0}^{n} \frac{\alpha_{m}}{\mathscr{A}_{m}} \leq \bar{\lambda}, \quad 1 \leq n \leq n_{1}-1, \\
1 & \leq n_{1} \leq s_{\max }=\max \left\{s: \sum_{0}^{s} \frac{\alpha_{m}}{\mathscr{A}_{m}} \leq \bar{\lambda}\right\} .
\end{aligned}
$$

Lemma 2.3. Let $\left\{\mu_{k}\right\},\left\{\alpha_{k}\right\},\left\{\beta_{k}\right\}$, and $\left\{\gamma_{k}\right\}$ be sequences of nonnegative real numbers satisfying the recurrence inequality

$$
\mu_{k+1} \leq \mu_{k}-\alpha_{k} \beta_{k}+\gamma_{k}
$$

Assume that

$$
\sum_{k=0}^{\infty} \alpha_{k}=\infty, \quad \sum_{k=1}^{\infty} \gamma_{k}<\infty .
$$

Then

(i) there exists an infinite subsequence $\left\{\beta_{\ell_{k}}\right\} \subset\left\{\beta_{k}\right\}$ such that

$$
\beta_{\ell_{k}} \leq \frac{1}{\sum_{j=1}^{\ell_{k}} \alpha_{j}}
$$

and, consequently, $\lim _{k \rightarrow \infty} \beta_{\ell_{k}}=0$;

(ii) if $\lim _{k \rightarrow \infty} \alpha_{k}=0$ and there exists $\kappa>0$ such that

$$
\left|\beta_{k+1}-\beta_{k}\right| \leq \kappa \alpha_{k}
$$

for all $k \geq 0$, then $\lim _{k \rightarrow \infty} \beta_{k}=0$.

LemmA 2.4. Let $\left\{\mu_{k}\right\},\left\{\alpha_{k}\right\},\left\{\beta_{k}\right\}$, and $\left\{\gamma_{k}\right\}$ be sequences of nonnegative real numbers satisfying the recurrence inequality (2.7). Assume that

$$
\sum_{k=0}^{\infty} \alpha_{k}=\infty, \quad \lim _{k \rightarrow \infty} \frac{\gamma_{k}}{\alpha_{k}}=0 .
$$

Then there exists an infinite subsequence $\left\{\beta_{\ell_{k}}\right\} \subset\left\{\beta_{k}\right\}$ such that $\lim _{k \rightarrow \infty} \beta_{\ell_{k}}=0$. 


\section{Retraction methods for weakly contractive mappings}

First of all, we consider the convergence of the retraction descent-like approximation method

$$
x_{n+1}=Q_{G}\left(x_{n}-\omega_{n}\left(x_{n}-A x_{n}\right)\right), \quad n=0,1,2, \ldots,
$$

where $Q_{G}$ is a nonexpansive retraction of $B$ onto the set $G$.

Theorem 3.1. Let $\left\{\omega_{n}\right\}$ be a sequence of positive numbers such that $\sum_{0}^{\infty} \omega_{n}=\infty$. Let $G$ be a closed convex subset of a Banach space B, and let $A$ be a weakly contractive mapping from $G$ into $B$ of the class $C_{\psi(t)}$ with a strictly increasing function $\psi(t)$. Suppose that the mapping A has a (unique) fixed point $x^{*} \in G$. Then

(i) the iterative sequence generated by (3.1), starting at $x_{0} \in G$, converges in norm to $x^{*}$ as $n \rightarrow \infty$;

(ii) $\left\|x_{n}-A x_{n}\right\| \rightarrow 0$ as $n \rightarrow \infty$;

(iii) the following estimate of the convergence rate holds

$$
\left\|x_{n}-x^{*}\right\| \leq \Phi^{-1}\left(\Phi\left(\left\|x_{0}-x^{*}\right\|\right)-\sum_{0}^{n-1} \omega_{n}\right)
$$

where $\Phi(t)$ is defined by the formula $\Phi(t)=\int d t / \psi(t)$ and $\Phi^{-1}$ is its inverse function.

Proof. Consider the sequence $\left\{x_{n}\right\}$ generated by (3.1). We have

$$
\begin{aligned}
\left\|x_{n+1}-x^{*}\right\| & =\left\|Q_{G}\left(x_{n}-\omega_{n}\left(x_{n}-A x_{n}\right)\right)-Q_{G} x^{*}\right\| \\
& \leq\left\|x_{n}-\omega_{n}\left(x_{n}-A x_{n}\right)-x^{*}\right\| \\
& =\left\|\left(1-\omega_{n}\right) x_{n}+\omega_{n} A x_{n}-\left(1-\omega_{n}\right) x^{*}-\omega_{n} x^{*}\right\| \\
& \leq\left(1-\omega_{n}\right)\left\|x_{n}-x^{*}\right\|+\omega_{n}\left\|A x_{n}-A x^{*}\right\| \\
& \leq\left(1-\omega_{n}\right)\left\|x_{n}-x^{*}\right\|+\omega_{n}\left\|x_{n}-x^{*}\right\|-\omega_{n} \psi\left(\left\|x_{n}-x^{*}\right\|\right) .
\end{aligned}
$$

Thus, for all $n \geq 0$,

$$
\left\|x_{n+1}-x^{*}\right\| \leq\left\|x_{n}-x^{*}\right\|-\omega_{n} \psi\left(\left\|x_{n}-x^{*}\right\|\right) .
$$

Now the claims (i), (ii), and (iii) follow from (3.4) and Lemma 2.1 because $\left\|x_{n}-A x_{n}\right\| \leq 2\left\|x_{n}-x^{*}\right\|$.

The following theorem provides other estimates of the convergence rate.

Theorem 3.2. Let $\left\{\omega_{n}\right\}$ be a sequence of positive numbers such that $\sum_{0}^{\infty} \omega_{n}=\infty$, $\omega_{n} \leq \omega$, and $\lim _{n \rightarrow \infty} \omega_{n}=0$. Let $G$ be a closed convex subset of Banach space $B$, 
and let $A$ be a weakly contractive mapping from $G$ into $B$ of the class $C_{\psi(t)}$ with a strictly increasing function $\psi(t)$. Suppose that the mapping $A$ has a (unique) fixed point $x^{*} \in G$. Then the iterative sequence generated by (3.1), starting at $x_{0} \in G$, converges in norm to $x^{*}$. Moreover, there exist a subsequence $\left\{x_{n_{l}}\right\} \subset\left\{x_{n}\right\}, l=$ $1,2, \ldots$, and constants $K>0$ and $R>0$ such that

$$
\left\|x_{n_{l}}-x^{*}\right\|^{2} \leq \psi_{1}^{-1}\left(\frac{1}{\sum_{0}^{n_{l}} \omega_{j}}+\frac{\gamma_{n_{l}}}{\omega_{n_{l}}}\right)
$$

where

$$
\begin{gathered}
\psi_{1}(t)=\sqrt{t} \psi(\sqrt{t}), \quad \gamma_{n}=2 L R^{2} \rho_{B}\left(8 K R^{-1} \omega_{n}\right), \\
\left\|x_{n_{l}+1}-x^{*}\right\|^{2} \leq \psi_{1}^{-1}\left(\frac{1}{\sum_{0}^{n_{l}} \omega_{j}}+\frac{\gamma_{n_{l}}}{\omega_{n_{l}}}\right)+\gamma_{n l}, \\
\left\|x_{n}-x^{*}\right\|^{2} \leq\left\|x_{n_{l}+1}-x^{*}\right\|^{2}-\sum_{n_{l}+1}^{n-1} \frac{\omega_{m}}{\mathscr{A}_{m}}, \quad n_{l}+1<n<n_{l+1}, \mathscr{A}_{m}=\sum_{0}^{m} \omega_{i}, \\
\left\|x_{n+1}-x^{*}\right\|^{2} \leq\left\|x_{0}-x^{*}\right\|^{2}-\sum_{0}^{n} \frac{\omega_{m}}{\mathscr{A}_{m}}, \quad 0 \leq n \leq n_{1}-1, \\
0 \leq n_{1} \leq s_{\max }=\max \left\{s: \sum_{0}^{s} \frac{\omega_{m}}{\mathscr{A}_{m}} \leq\left\|x_{0}-x^{*}\right\|^{2}\right\} .
\end{gathered}
$$

Proof. By (3.4),

$$
\left\|x_{n+1}-x^{*}\right\| \leq\left\|x_{n}-x^{*}\right\| \leq\left\|x_{0}-x^{*}\right\|=K
$$

for all $n \geq 0$. Thus $\left\|x_{n}-A x_{n}\right\| \leq 2 K$ and

$$
\left\|x_{n}\right\| \leq\left\|x_{n}-x^{*}\right\|+\left\|x^{*}\right\| \leq K+\left\|x^{*}\right\|=C .
$$

Set $\phi_{n}=x_{n}-\omega_{n}\left(x_{n}-A x_{n}\right)$. Since $Q_{G}$ is a nonexpansive retraction and $\|x\|^{2}$ is a convex functional, we have

$$
\begin{aligned}
\left\|x_{n+1}-x^{*}\right\|^{2} \leq & \left\|x_{n}-\omega_{n}\left(x_{n}-A x_{n}\right)-x^{*}\right\|^{2}=\left\|\phi_{n}-x^{*}\right\|^{2} \\
\leq & \left\|x_{n}-x^{*}\right\|^{2}-2 \omega_{n}\left\langle x_{n}-A x_{n}, J\left(\phi_{n}-x^{*}\right)\right\rangle \\
= & \left\|x_{n}-x^{*}\right\|^{2}-2 \omega_{n}\left\langle x_{n}-A x_{n}, J\left(x_{n}-x^{*}\right)\right\rangle \\
& +2\left\langle\phi_{n}-x_{n}, J\left(\phi_{n}-x^{*}\right)-J\left(x_{n}-x^{*}\right)\right\rangle .
\end{aligned}
$$


By (1.11), if $\|x\| \leq R$ and $\|y\| \leq R$, then

$$
\langle x-y, J x-J y\rangle \leq 2 L R^{2} \rho_{B}\left(4 R^{-1}\|x-y\|\right) .
$$

Therefore,

$$
\left\|x_{n+1}-x^{*}\right\|^{2} \leq\left\|x_{n}-x^{*}\right\|^{2}-2 \omega_{n} \psi\left(\left\|x_{n}-x^{*}\right\|\right)\left\|x_{n}-x^{*}\right\|+2 \gamma_{n}
$$

where

$$
\gamma_{n}=\left\langle\phi_{n}-x_{n}, J\left(\phi_{n}-x^{*}\right)-J\left(x_{n}-x^{*}\right)\right\rangle \leq 2 L R^{2} \rho_{B}\left(8 K R^{-1} \omega_{n}\right) .
$$

Here we used the estimates $\left\|\phi_{n}\right\| \leq C+2 \omega K=R$ and $\left\|x_{n}\right\| \leq C \leq R$. It is obvious that

$$
\frac{\gamma_{n}}{\omega_{n}} \longrightarrow 0 \quad \text { as } n \longrightarrow \infty
$$

because $B$ is a uniformly smooth space. Thus, we get for $\lambda_{n}=\left\|x_{n}-x^{*}\right\|^{2}$ the following recursive inequality:

$$
\lambda_{n+1} \leq \lambda_{n}-2 \omega_{n} \psi_{1}\left(\lambda_{n}\right)+2 \gamma_{n}
$$

The strong convergence of $\left\{x_{n}\right\}$ to $x^{*}$ and the estimates (3.5), (3.6), (3.7), (3.8), (3.9), and (3.10) now follow from Lemma 2.2.

Next we will study the iterative method (3.1) with perturbed mappings $A_{n}$ : $G \rightarrow B:$

$$
y_{n+1}=Q_{G}\left(y_{n}-\omega_{n}\left(y_{n}-A_{n} y_{n}\right)\right), \quad n=0,1,2, \ldots
$$

provided that the sequence $\left\{A_{n}\right\}$ satisfies the following condition:

$$
\left\|A_{n} v-A v\right\| \leq h_{n} g(\|v\|)+\delta_{n} \quad \forall v \in G
$$

THeOrem 3.3. Let $\left\{\omega_{n}\right\}$ be a sequence of positive numbers such that $\sum_{0}^{\infty} \omega_{n}=\infty$ and $\omega \geq \omega_{n}>0$. Let $G$ be a closed convex subset of the Banach space B, let $A$ be a weakly contractive mapping from $G$ into $B$ of the class $C_{\psi(t)}$ with a strictly increasing function $\psi(t)$, and let $x^{*} \in G$ be its unique fixed point. Suppose that there exist sequences of positive numbers $\left\{\delta_{n}\right\}$ and $\left\{h_{n}\right\}$ converging to 0 as $n \rightarrow \infty$, and a 
positive function $g(t)$ defined on $\mathbb{R}^{+}$and bounded on bounded subsets of $\mathbb{R}^{+}$such that (3.20) is satisfied for all $n \geq 0$. If the sequence generated by (3.19) and starting at an arbitrary $y_{0} \in G$ is bounded, then it converges in norm to the point $x^{*}$. If, in addition, $\lim _{n \rightarrow \infty} \omega_{n}=0$, then there exist a subsequence $\left\{y_{n_{l}}\right\} \subset\left\{y_{n}\right\}, l=1,2, \ldots$, converging to $x^{*}$ as $l \rightarrow \infty$ and a constant $K>0$ such that

$$
\left\|y_{n_{l}}-x^{*}\right\|^{2} \leq \psi_{1}^{-1}\left(\frac{1}{\sum_{1}^{n_{l}} \omega_{j}}+h_{n_{l}} g(K)+\delta_{n_{l}}\right)
$$

Proof. Similarly to the proof of Theorem 3.1, we get, for all $n \geq 0$, the inequality

$$
\begin{aligned}
\left\|y_{n+1}-x^{*}\right\| & =\left\|Q_{G}\left(y_{n}-\omega_{n}\left(y_{n}-A_{n} y_{n}\right)\right)-Q_{G} x^{*}\right\| \\
& \leq\left\|y_{n}-\omega_{n}\left(y_{n}-A_{n} y_{n}\right)-x^{*}\right\| \\
& =\left\|\left(1-\omega_{n}\right) y_{n}+\omega_{n} A_{n} y_{n}-\left(1-\omega_{n}\right) x^{*}-\omega_{n} x^{*}\right\| \\
& \leq\left(1-\omega_{n}\right)\left\|y_{n}-x^{*}\right\|+\omega_{n}\left\|A_{n} y_{n}-A x^{*}\right\| \\
& \leq\left(1-\omega_{n}\right)\left\|y_{n}-x^{*}\right\|+\omega_{n}\left\|A y_{n}-A x^{*}\right\|+\omega_{n}\left\|A_{n} y_{n}-A y_{n}\right\| \\
& \leq\left\|y_{n}-x^{*}\right\|-\omega_{n} \psi\left(\left\|y_{n}-x^{*}\right\|\right)+\omega_{n}\left(h_{n} g\left(\left\|y_{n}\right\|\right)+\delta_{n}\right) .
\end{aligned}
$$

By our assumptions, there exists $K>0$ such that $\left\|y_{n}\right\| \leq K$. Hence,

$$
\left\|y_{n+1}-x^{*}\right\| \leq\left\|y_{n}-x^{*}\right\|-\omega_{n} \psi\left(\left\|y_{n}-x^{*}\right\|\right)+\omega_{n}\left(h_{n} g(K)+\delta_{n}\right)
$$

for some constant $C_{1}>0$. Since

$$
\frac{\omega_{n}\left(h_{n} g(K)+\delta_{n}\right)}{\omega_{n}} \longrightarrow 0 \text { as } n \longrightarrow \infty
$$

we conclude, again, by Lemma 2.2 that $y_{n} \rightarrow x^{*}$. The estimate (3.21) is obtained as in the proof of Theorem 3.2.

Let $G_{1}$ and $G_{2}$ be closed convex subsets of $B$. The Hausdorff distance between $G_{1}$ and $G_{2}$ is defined by the following formula:

$$
\mathscr{H}\left(G_{1}, G_{2}\right)=\max \left\{\sup _{z_{1} \in G_{1}} \inf _{z_{2} \in G_{2}}\left\|z_{1}-z_{2}\right\|, \sup _{z_{1} \in G_{2}} \inf _{z_{2} \in G_{1}}\left\|z_{1}-z_{2}\right\|\right\} .
$$

In order to prove the next theorem, we need the following lemma.

Lemma 3.4. If $B$ is a uniformly smooth Banach space, and if $\Omega_{1}$ and $\Omega_{2}$ are closed convex subsets of $B$ such that the Hausdorff distance $\mathcal{H}\left(\Omega_{1}, \Omega_{2}\right) \leq \sigma, h_{B}(\tau)=$ $\rho_{B}(\tau) / \tau$, and $Q_{\Omega_{1}}$ and $Q_{\Omega_{2}}$ are the sunny nonexpansive retractions onto the subsets 
$\Omega_{1}$ and $\Omega_{2}$, respectively, then

$$
\left\|Q_{\Omega_{1}} x-Q_{\Omega_{2}} x\right\|^{2} \leq 16 R(2 r+d) h_{B}\left(16 L R^{-1} \sigma\right),
$$

where $L$ is the Figiel constant, $r=\|x\|, d=\max \left\{d_{1}, d_{2}\right\}$, and $R=2(2 r+d)+\sigma$. Here $d_{i}=\operatorname{dist}\left(\theta, \Omega_{i}\right), i=1,2$, and $\theta$ is the origin of the space $B$.

Proof. Denote $\breve{x}_{1}=Q_{\Omega_{1}} x$ and $\breve{x}_{2}=Q_{\Omega_{2}} x$. Since $\mathscr{H}\left(\Omega_{1}, \Omega_{2}\right) \leq \sigma$, there exists $\xi_{1} \in$ $\Omega_{1}$ such that $\left\|\breve{x}_{2}-\xi_{1}\right\| \leq \sigma$. Now

$$
\begin{aligned}
\left\langle x-\breve{x}_{1}, J\left(\breve{x}_{2}-\breve{x}_{1}\right)\right\rangle & =\left\langle x-\breve{x}_{1}, J\left(\xi_{1}-\breve{x}_{1}\right)\right\rangle+\left\langle x-\breve{x}_{1}, J\left(\breve{x}_{2}-\breve{x}_{1}\right)-J\left(\xi_{1}-\breve{x}_{1}\right)\right\rangle \\
& \leq\left\|x-\breve{x}_{1}\right\|\left\|J\left(\breve{x}_{2}-\breve{x}_{1}\right)-J\left(\xi_{1}-\breve{x}_{1}\right)\right\|,
\end{aligned}
$$

because $\left\langle x-\breve{x}_{1}, J\left(\xi_{1}-\breve{x}_{1}\right)\right\rangle \leq 0$ by (1.18). It is obvious that

$$
\begin{aligned}
\left\|x-\breve{x}_{1}\right\| & \leq\left\|x-Q_{\Omega_{1}} \theta\right\|+\left\|Q_{\Omega_{1}} \theta-Q_{\Omega_{1}} x\right\| \leq 2\|x\|+\left\|Q_{\Omega_{1}} \theta\right\| \leq 2 r+d, \\
\left\|x-\breve{x}_{2}\right\| & \leq\left\|x-Q_{\Omega_{2}} \theta\right\|+\left\|Q_{\Omega_{2}} \theta-Q_{\Omega_{2}} x\right\| \leq 2\|x\|+\left\|Q_{\Omega_{2}} \theta\right\| \leq 2 r+d, \\
\left\|\breve{x}_{1}-\breve{x}_{2}\right\| & \leq\left\|\breve{x}_{1}-x\right\|+\left\|x-\breve{x}_{2}\right\| \leq 2(2 r+d), \\
\left\|\breve{x}_{1}-\xi_{1}\right\| & \leq\left\|\breve{x}_{1}-\breve{x}_{2}\right\|+\left\|\breve{x}_{2}-\xi_{1}\right\| \leq 2(2 r+d)+\sigma .
\end{aligned}
$$

If $R=2(2 r+d)+\sigma$, then by $(1.13)$

$$
\begin{aligned}
\left\langle x-\breve{x}_{1}, J\left(\breve{x}_{2}-\breve{x}_{1}\right)\right\rangle & \leq 8 R\left\|x-\breve{x}_{1}\right\| h_{B}\left(16 L R^{-1}\left\|\breve{x}_{2}-\xi_{1}\right\|\right) \\
& \leq 8 R(2 r+d) h_{B}\left(16 L R^{-1} \sigma\right) .
\end{aligned}
$$

In the same way, we see that there exists $\xi_{2} \in \Omega_{2}$ such that $\left\|\breve{x}_{1}-\xi_{2}\right\| \leq \sigma$ and

$$
\begin{aligned}
\left\langle x-\breve{x}_{2}, J\left(\breve{x}_{1}-\breve{x}_{2}\right)\right\rangle & =\left\langle x-\breve{x}_{2}, J\left(\xi_{2}-\breve{x}_{2}\right)\right\rangle+\left\langle x-\breve{x}_{2}, J\left(\breve{x}_{1}-\breve{x}_{2}\right)-J\left(\xi_{2}-\breve{x}_{2}\right)\right\rangle \\
& \leq\left\|x-\breve{x}_{2}\right\|\left\|J\left(\breve{x}_{1}-\breve{x}_{2}\right)-J\left(\xi_{2}-\breve{x}_{2}\right)\right\|,
\end{aligned}
$$

because $\left\langle x-\breve{x}_{2}, J\left(\xi_{2}-\breve{x}_{2}\right)\right\rangle \leq 0$. As above,

$$
\left\|\breve{x}_{2}-\xi_{2}\right\| \leq\left\|\breve{x}_{1}-\breve{x}_{2}\right\|+\left\|\breve{x}_{1}-\xi_{2}\right\| \leq 2(2 r+d)+\sigma,
$$


and if, again, $R=2(2 r+d)+\sigma$, we have

$$
\begin{aligned}
\left\langle x-\breve{x}_{2}, J\left(\breve{x}_{1}-\breve{x}_{2}\right)\right\rangle & \leq 8 R\left\|x-\breve{x}_{2}\right\| h_{B}\left(16 L R^{-1}\left\|\breve{x}_{1}-\xi_{2}\right\|\right) \\
& \leq 8 R(2 r+d) h_{B}\left(16 L R^{-1} \sigma\right) .
\end{aligned}
$$

Therefore, the estimate (3.26) holds by (3.29) and (3.32). Lemma 3.4 is proved.

Next we will study the iterative method (3.1) with perturbed sets $G_{n}$ :

$$
z_{n+1}=Q_{G_{n+1}}\left(z_{n}-\omega_{n}\left(z_{n}-A z_{n}\right)\right), \quad n=0,1,2, \ldots
$$

Theorem 3.5. Let $G \subset D(A)$ and $G_{n} \subset D(A), n=0,1,2, \ldots$, be closed convex subsets of $B$ such that the Hausdorff distance $\mathscr{H}\left(G_{n}, G\right) \leq \sigma_{n} \leq \sigma$, and let $A$ be a weakly contractive mapping from $D(A)$ into $B$ of the class $C_{\psi(t)}$ with a strictly increasing function $\psi(t)$. Suppose that the mapping $A$ has a (unique) fixed point $x^{*} \in G$. Assume that $\sum_{0}^{\infty} \omega_{n}=\infty, \omega_{n} \leq \omega$, and that

$$
\frac{\sqrt{h_{B}\left(\sigma_{n}\right)}}{\omega_{n}} \longrightarrow 0 \text { as } n \longrightarrow \infty \text {. }
$$

If the iterative sequence (3.33), starting at an arbitrary point $z_{0} \in G_{0}$, is bounded, then it converges in norm to $x^{*}$.

Proof. For all $n \geq 0$, we have

$$
\left\|z_{n+1}-x^{*}\right\| \leq\left\|z_{n+1}-x_{n+1}\right\|+\left\|x_{n+1}-x^{*}\right\|
$$

where the sequence $\left\{x_{n}\right\}$ is generated by (3.1), and therefore,

$$
\left\|x_{n}-x^{*}\right\| \longrightarrow 0 \text { as } n \rightarrow \infty
$$

We will show that

$$
\left\|z_{n}-x_{n}\right\| \longrightarrow 0 \text { as } n \longrightarrow \infty
$$

We have

$$
\begin{aligned}
\left\|z_{n+1}-x_{n+1}\right\|= & \left\|Q_{G_{n+1}}\left(z_{n}-\omega_{n}\left(z_{n}-A z_{n}\right)\right)-Q_{G}\left(x_{n}-\omega_{n}\left(x_{n}-A x_{n}\right)\right)\right\| \\
\leq & \left\|Q_{G}\left(z_{n}-\omega_{n}\left(z_{n}-A z_{n}\right)\right)-Q_{G}\left(x_{n}-\omega_{n}\left(x_{n}-A x_{n}\right)\right)\right\| \\
& +\left\|Q_{G_{n+1}}\left(z_{n}-\omega_{n}\left(z_{n}-A z_{n}\right)\right)-Q_{G}\left(z_{n}-\omega_{n}\left(z_{n}-A z_{n}\right)\right)\right\| .
\end{aligned}
$$


It is easy to check that

$$
\begin{aligned}
\| Q_{G}\left(z_{n}-\right. & \left.\omega_{n}\left(z_{n}-A z_{n}\right)\right)-Q_{G}\left(x_{n}-\omega_{n}\left(x_{n}-A x_{n}\right)\right) \| \\
& \leq\left(1-\omega_{n}\right)\left\|z_{n}-x_{n}\right\|+\omega_{n}\left\|A z_{n}-A x_{n}\right\| \\
& \leq\left\|z_{n}-x_{n}\right\|-\omega_{n} \psi\left(\left\|z_{n}-x_{n}\right\|\right) .
\end{aligned}
$$

If $\left\|z_{n}\right\| \leq K$, then $\left\|z_{n}-A z_{n}\right\| \leq 2\left\|z_{n}-x^{*}\right\| \leq 2\left(K+\left\|x^{*}\right\|\right)$ and there exists a constant $r>0$ such that $\left\|z_{n}-\omega_{n}\left(z_{n}-A z_{n}\right)\right\| \leq r$. By Lemma 3.4,

$$
\begin{gathered}
\left\|Q_{G_{n+1}}\left(z_{n}-\omega_{n}\left(z_{n}-A z_{n}\right)\right)-Q_{G}\left(z_{n}-\omega_{n}\left(z_{n}-A z_{n}\right)\right)\right\|^{2} \\
\leq 16 R(2 r+d) h_{B}\left(16 L R^{-1} \sigma_{n+1}\right)
\end{gathered}
$$

where $R=2(2 r+d)+\sigma, d=\max \left\{d_{1}, d_{2}\right\}, d_{1}=\operatorname{dist}(\theta, G), d_{2}=\sup _{n}\left\{\operatorname{dist}\left(\theta, G_{n}\right)\right\}$, and $\theta$ is the origin of the space $B$. Hence,

$$
\begin{aligned}
& \left\|z_{n+1}-x_{n+1}\right\| \\
& \quad \leq\left\|z_{n}-x_{n}\right\|-\omega_{n} \psi\left(\left\|z_{n}-x_{n}\right\|\right)+\left(16 R(2 r+d) h_{B}\left(16 L R^{-1} \sigma_{n+1}\right)\right)^{1 / 2} .
\end{aligned}
$$

Since $\omega_{n}^{-1} \sqrt{h_{B}\left(\sigma_{n}\right)} \rightarrow 0,(3.37)$ is, indeed, true. Theorem 3.5 is proved.

Next we study the method of successive approximations

$$
x_{n+1}=Q_{G} A x_{n}, \quad n=0,1,2, \ldots
$$

where $Q_{G}$ is the sunny nonexpansive retraction of $B$ onto its subset $G$.

Theorem 3.6. Suppose that $B$ is a uniformly smooth Banach space, and $A: G \rightarrow B$ is a weakly contractive mapping from a closed convex subset $G$ into $B$ of the class $C_{\psi(t)}$ with a strictly increasing function $\psi(t)$. Suppose that the mapping $A$ has a (unique) fixed point $x^{*} \in G$. Consider the sequence $\left\{x_{n}\right\}$ generated by (3.42). Then

(i) the sequence $\left\{x_{n}\right\}$ is bounded;

(ii) the sequence $\left\{x_{n}\right\}$ strongly converges to $x^{*}$;

(iii) the following estimate of the convergence rate holds:

$$
\left\|x_{n}-x^{*}\right\|^{2} \leq \Phi^{-1}\left(\Phi\left(\left\|x_{0}-x^{*}\right\|^{2}\right)-(n-1)\right),
$$

where $\Phi(t)$ is defined by the formula $\Phi(t)=\int d t / \psi_{1}(t)$ with $\psi_{1}(t)=$ $\sqrt{t} \psi(\sqrt{t})$ and $\Phi^{-1}$ is its inverse function. 
Proof. By (3.42), we have

$$
\begin{aligned}
\left\|x_{n+1}-x^{*}\right\|^{2} & =\left\|Q_{G} A x_{n}-x^{*}\right\|^{2}=\left\|Q_{G} A x_{n}-Q_{G} A x^{*}\right\|^{2} \\
& \leq\left\|A x_{n}-A x^{*}\right\|^{2} \leq\left\|x_{n}-x^{*}\right\|^{2}-\psi\left(\left\|x_{n}-x^{*}\right\|\right)\left\|x_{n}-x^{*}\right\| .
\end{aligned}
$$

Denoting $\left\|x_{n}-x^{*}\right\|^{2}$ by $\lambda_{n}$, we see that

$$
\lambda_{n+1} \leq \lambda_{n}-\psi_{1}\left(\lambda_{n}\right)
$$

and therefore, our claims follow from Lemma 2.1.

As before, we can also consider the method of successive approximations with perturbed sets $G_{n}$,

$$
z_{n+1}=Q_{G_{n+1}} A z_{n}, \quad n=0,1,2, \ldots
$$

Theorem 3.7. Let $G \subset D(A)$ and $G_{n} \subset D(A), n=0,1,2, \ldots$, be closed convex subsets of $B$ such that the Hausdorff distance $\mathscr{H}\left(G_{n}, G\right) \leq \sigma_{n} \leq \sigma$, and let $A$ be a weakly contractive mapping from $D(A)$ into $B$ of the class $C_{\psi(t)}$ with a strictly increasing function $\psi(t)$. Suppose that the mapping $A$ has a (unique) fixed point $x^{*} \in G$. If $\sigma_{n} \rightarrow 0$ as $n \rightarrow \infty$, then the iterative sequence (3.46), starting at an arbitrary point $z_{0} \in G_{0}$, converges in norm to $x^{*}$.

Proof. For all $n \geq 0$, we can write

$$
\begin{aligned}
\left\|z_{n+1}-x^{*}\right\| & =\left\|Q_{G_{n+1}} A z_{n}-A x^{*}\right\| \\
& \leq\left\|Q_{G_{n+1}} A z_{n}-Q_{G_{n+1}} A x^{*}\right\|+\left\|Q_{G_{n+1}} x^{*}-Q_{G} x^{*}\right\| .
\end{aligned}
$$

Since $Q_{G_{n}}$ is nonexpansive for each $n$, the inequality

$$
\left\|Q_{G_{n+1}} A z_{n}-Q_{G_{n+1}} A x^{*}\right\| \leq\left\|A z_{n}-A x^{*}\right\|
$$

also holds. The second term in (3.47) is estimated by Lemma 3.4. There exists a constant $C>0$ such that

$$
\left\|Q_{G_{n+1}} x^{*}-Q_{G} x^{*}\right\| \leq C \sqrt{h_{B}\left(\sigma_{n+1}\right)} .
$$

Thus,

$$
\left\|z_{n+1}-x^{*}\right\| \leq\left\|z_{n}-x^{*}\right\|-\psi\left(\left\|z_{n}-x^{*}\right\|\right)+C \sqrt{h_{B}\left(\sigma_{n+1}\right)}
$$

and the theorem follows from Lemma 2.2. 


\section{Retraction methods for nonexpansive mappings}

First, we are going to consider the following proximal retraction method:

(1) take an arbitrary $x_{0} \in G$;

(2) given $x_{n} \in G$, define $x_{n+1} \in G$ by the system

$$
0=\lambda_{n} F\left(Q_{G}(y)\right)+y-x_{n}, \quad x_{n+1}=Q_{G}(y),
$$

with $\lambda_{n}>0$. Here $F=I-A$, where $A: D(A) \subset B \rightarrow B$ is a nonexpansive operator.

In order to prove Theorem 4.2 we need the following lemma [1].

Lemma 4.1. If $F=I-A$ with a nonexpansive mapping $A$, then for all $x, y \in D(A)$,

$$
\langle F x-F y, J(x-y)\rangle \geq R_{1}^{2} \delta_{B}\left(\frac{\|F x-F y\|}{2 R_{1}}\right),
$$

where

$$
R_{1}=\sqrt{\frac{\|x-y\|^{2}+\|A x-A y\|^{2}}{2}} \leq\|x-y\| .
$$

If $\|x\| \leq R$ and $\|y\| \leq R$, with $x, y \in D(A)$, then $R_{1} \leq 2 R$ and

$$
\langle F x-F y, J(x-y)\rangle \geq L^{-1} R^{2} \delta_{B}\left(\frac{\|F x-F y\|}{4 R}\right)
$$

Theorem 4.2. Suppose that $B$ is a uniformly convex and uniformly smooth Banach space, $A: G \subset B \rightarrow B$ is a nonexpansive operator, $G$ is a closed convex subset of $B$, and the fixed point set $M$ of $A$ is not empty. Let $\left\{x_{n}\right\}$ be any sequence of iterates generated by (4.1). Then the following statements hold:

(i) $\left\{x_{n}\right\}$ is bounded and $\left\|x_{n+1}-x_{n}\right\| \rightarrow 0$ as $n \rightarrow \infty$.

If, in addition, $\lambda_{n} \geq \lambda>0$, then

(ii) there exists

$$
\lim _{n \rightarrow \infty}\left\langle F\left(x_{n}\right), J\left(x_{n}-x^{*}\right)\right\rangle=0 \quad \forall x^{*} \in M
$$

(iii) there exists a weak accumulation point $\tilde{x}$ of $\left\{x_{n}\right\}$;

(iv) all weak accumulation points of $\left\{x_{n}\right\}$ belong to $M$;

(v) if $M$ is a singleton, that is, $M=\{\tilde{x}\}$, then $\left\{x_{n}\right\}$ converges weakly to $\tilde{x}$;

(vi) if $J$ is weakly sequentially continuous on a bounded set containing $\left\{x_{n}\right\}$, then $\left\{x_{n}\right\}$ weakly converges to a point $\tilde{x} \in M$. 
Proof. The following inequalities follow from the convexity of the functional $\|x\|^{2}$ on any Banach space; they are valid for all $y \in B$ :

$$
\begin{aligned}
\left\|x_{n+1}-x^{*}\right\|^{2} \leq & \left\|x_{n}-x^{*}\right\|^{2}+2\left\langle x_{n+1}-x_{n}, J\left(x_{n+1}-x^{*}\right)\right\rangle \\
= & \left\|x_{n}-x^{*}\right\|^{2}+2\left\langle x_{n+1}-y, J\left(x_{n+1}-x^{*}\right)\right\rangle \\
& +2\left\langle y-x_{n}, J\left(x_{n+1}-x^{*}\right)\right\rangle .
\end{aligned}
$$

Since $x_{n+1}=Q_{G}(y)$ and $x^{*} \in G$, we have (see Proposition 1.4)

$$
\left\langle x_{n+1}-y, J\left(x_{n+1}-x^{*}\right)\right\rangle \leq 0 .
$$

Therefore, (4.1) implies that

$$
\begin{aligned}
\left\|x_{n+1}-x^{*}\right\|^{2} & \leq\left\|x_{n}-x^{*}\right\|^{2}+2\left\langle y-x_{n}, J\left(x_{n+1}-x^{*}\right)\right\rangle \\
& =\left\|x_{n}-x^{*}\right\|^{2}-2 \lambda_{n}\left\langle F\left(x_{n+1}\right), J\left(x_{n+1}-x^{*}\right)\right\rangle .
\end{aligned}
$$

From the last inequality, we conclude that

$$
\left\|x_{n+1}-x^{*}\right\| \leq\left\|x_{n}-x^{*}\right\| \leq\left\|x_{1}-x^{*}\right\|
$$

because

$$
\left\langle F\left(x_{n}\right), J\left(x_{n}-x^{*}\right)\right\rangle \geq 0, \quad \lambda_{n}>0
$$

for all $n \geq 0$. Thus, the sequence $\left\{x_{n}\right\}$ is bounded, say by $R$, and the functional $\left\|x_{n}-x^{*}\right\|^{2}$ has a limit $a\left(x^{*}\right) \geq 0$. In addition, if $\lambda_{n} \geq \lambda>0$, then

$$
\lim _{n \rightarrow \infty}\left\langle F\left(x_{n}\right), J\left(x_{n}-x^{*}\right)\right\rangle=0 .
$$

Every bounded set in a reflexive Banach space is relatively weakly compact. This means that there exists some subsequence $\left\{x_{n_{k}}\right\} \subseteq\left\{x_{n}\right\}$ which weakly converges to a limit point $\tilde{x}$. Since $G$ is closed and convex, it is also weakly closed. Therefore $\tilde{x} \in G$. By Lemma 4.1,

$$
\left\langle F\left(x_{n}\right), J\left(x_{n}-x^{*}\right)\right\rangle \geq L^{-1} \bar{R}^{2} \delta_{B}\left(\frac{\left\|F x_{n}\right\|}{4 \bar{R}}\right)
$$

because

$$
\begin{gathered}
\left\|x_{n}-x^{*}\right\| \leq R+\left\|x^{*}\right\|=\bar{R}, \\
\left\|x_{n}-x^{*}-F x_{n}\right\| \leq\left\|A x_{n}-A x^{*}\right\| \leq\left\|x_{n}-x^{*}\right\| \leq \bar{R} .
\end{gathered}
$$


Hence, by (4.11), we obtain

$$
\lim _{n \rightarrow \infty} F x_{n}=0
$$

It is clear that $\tilde{x} \in M$ because the operator $A$ is demiclosed. Thus, all weak accumulation points of $\left\{x_{n}\right\}$ belong to $M$. If $M$ is a singleton, then the whole sequence $\left\{x_{n}\right\}$ converges weakly to $\tilde{x}$. Otherwise, we will prove claim (vi) by contradiction.

Assume there are two weak accumulation points of the sequence $\left\{x_{n}\right\}$ which belong to $M$,

$$
w-\lim _{k \rightarrow \infty} x_{n_{k}}=\tilde{x}_{1}, \quad w-\lim _{l \rightarrow \infty} x_{n_{l}}=\tilde{x}_{2}
$$

Then, since the functional $\|\cdot\|^{2}$ is convex, we have

$$
\left\|x_{n}-\tilde{x}_{1}\right\|^{2}-\left\|x_{n}-\tilde{x}_{2}\right\|^{2} \leq 2\left\langle\tilde{x}_{1}-\tilde{x}_{2}, J\left(\tilde{x}_{1}-x_{n}\right)\right\rangle .
$$

Applying the first limit in (4.15) and the weak sequential continuity of $J$, we get from (4.16),

$$
\lim _{k \rightarrow \infty}\left\|x_{n_{k}}-\tilde{x}_{1}\right\|^{2}-\lim _{k \rightarrow \infty}\left\|x_{n_{k}}-\tilde{x}_{2}\right\|^{2}=a\left(\tilde{x}_{1}\right)-a\left(\tilde{x}_{2}\right) \leq 0 .
$$

By analogy, the convexity of $\|\cdot\|^{2}$ yields

$$
\left\|x_{n}-\tilde{x}_{2}\right\|^{2}-\left\|x_{n}-\tilde{x}_{1}\right\|^{2} \leq 2\left\langle\tilde{x}_{2}-\tilde{x}_{1}, J\left(\tilde{x}_{2}-x_{n}\right)\right\rangle .
$$

The second limit in (4.15) now implies that

$$
\lim _{l \rightarrow \infty}\left\|x_{n_{l}}-\tilde{x}_{2}\right\|^{2}-\lim _{l \rightarrow \infty}\left\|x_{n_{l}}-\tilde{x}_{1}\right\|^{2}=a\left(\tilde{x}_{2}\right)-a\left(\tilde{x}_{1}\right) \leq 0 .
$$

Now we conclude, from (4.17) and (4.19), that $a\left(\tilde{x}_{1}\right)=a\left(\tilde{x}_{2}\right)$. Hence,

$$
\lim _{n \rightarrow \infty}\left\|x_{n}-\tilde{x}\right\|^{2}=a \quad \forall \tilde{x} \in M
$$

Consider $\tilde{x}=2^{-1}\left(\tilde{x}_{1}+\tilde{x}_{2}\right)$. It is obvious that $\tilde{x} \in M$ because $M$ is convex. Since the space $B$ is uniformly convex, the assumption that $\tilde{x}_{1} \neq \tilde{x}_{2}$ leads to $a(\tilde{x})<$ $a\left(\tilde{x}_{1}\right)=a\left(\tilde{x}_{2}\right)$ which contradicts (4.20). Theorem 4.2 is proved.

Corollary 4.3. Under the conditions of Theorem 4.2, the following statements hold:

(i) if $\left\{x_{n}\right\}$ is bounded, then a fixed point $x^{*}$ of A exists;

(ii) if $x^{*}$ exists, then $\left\{x_{n}\right\}$ is bounded;

(iii) if $M=\varnothing$, then $\left\|x_{n}\right\| \rightarrow \infty$. 
Now we study the convergence of the descent-like approximation method (3.1) for nonexpansive maps.

Theorem 4.4. Suppose that $B$ is a uniformly convex and uniformly smooth Banach space, $A: G \subset B \rightarrow B$ is a nonexpansive operator, $G$ is a closed convex subset of $B$, and the fixed point set $M$ of $A$ is not empty. Let $\left\{x_{n}\right\}$ be any sequence of iterates generated by the algorithm (3.1). Then, the following assertions hold:

(1) if $\omega_{n} \rightarrow 0$ as $n \rightarrow \infty$, then $\left\|x_{n+1}-x_{n}\right\| \rightarrow 0$;

(2) if, in addition, the limit of the sequence $\left\{\left\|F\left(x_{n}\right)\right\|\right\}$ exists and $\sum_{k=0}^{\infty} \omega_{n}=\infty$, then the statements (iii), (iv), (v), and (vi) of Theorem 4.2 are all true.

Proof. It was shown in Theorem 3.1 that the sequence $\left\{x_{n}\right\}$ is bounded, say by $R$, and that the sequence $\left\{\left\|x_{n}-x^{*}\right\|\right\}$, where $x^{*} \in M$, is convergent. Thus, $\left\{x_{n}-\right.$ $\left.A x_{n}\right\}$ is bounded by $\bar{R}=2\left(R+\left\|x^{*}\right\|\right)$. Therefore, assertion (1) is obtained from the following estimate:

$$
\begin{aligned}
\left\|x_{n+1}-x_{n}\right\| & =\left\|Q_{G}\left(x_{n}-\omega_{n}\left(x_{n}-A x_{n}\right)\right)-Q_{G} x_{n}\right\| \\
& \leq \omega_{n}\left\|x_{n}-A x_{n}\right\| \leq \bar{R} \omega_{n} \longrightarrow 0 .
\end{aligned}
$$

Furthermore, there exists a subsequence $\left\{x_{n_{k}}\right\} \subseteq\left\{x_{n}\right\}$ which weakly converges to a limit point $\tilde{x} \in G$. Take any $x^{*} \in M$. Using (3.13), (3.14), and Lemma 4.1, we obtain

$$
\begin{aligned}
& \left\|x_{n+1}-x^{*}\right\|^{2} \\
& \quad \leq\left\|x_{n}-x^{*}\right\|^{2}-(2 L)^{-1} \bar{R}^{2} \omega_{n} \delta_{B}\left((2 \bar{R})^{-1}\left\|x_{n}-A x_{n}\right\|\right)+2^{-1} L \bar{R}^{2} \rho_{B}\left(8 \omega_{n}\right) .
\end{aligned}
$$

Since the space $B$ is uniformly smooth,

$$
\frac{\rho_{B}\left(\omega_{n}\right)}{\omega_{n}} \longrightarrow 0 \quad \text { as } n \longrightarrow \infty
$$

Thus, by Lemma 2.4, there exists an infinite subsequence $\left\{\ell_{k}\right\} \subset\{n\}$ such that

$$
\lim _{k \rightarrow \infty} \delta_{B}\left((2 \bar{R})^{-1}\left\|x_{\ell_{k}}-A x_{\ell_{k}}\right\|\right)=0
$$

Since the space $B$ is uniformly convex, the properties of the function $\delta_{B}(\varepsilon)$ imply that

$$
\lim _{k \rightarrow \infty}\left\|F x_{\ell_{k}}\right\|=0
$$


Finally, by the condition $\lim _{n \rightarrow \infty}\left\|F x_{n}\right\|=d \geq 0$, we get

$$
\lim _{n \rightarrow \infty} F x_{n}=0
$$

The rest of the proof follows the pattern of the proof of Theorem 4.2.

The following corollary is valid for self-mappings $A: G \rightarrow G$ and the method

$$
x_{n+1}=x_{n}-\omega_{n}\left(x_{n}-A x_{n}\right), \quad n=0,1,2, \ldots
$$

Corollary 4.5. Suppose that $B$ is a uniformly convex and uniformly smooth $B a$ nach space, $A: G \rightarrow G$ is a nonexpansive operator, $G$ is a closed convex subset of $B$, and that the fixed point set $M$ of $A$ is not empty. Let $\left\{x_{n}\right\}$ be any sequence of iterates generated by the algorithm (4.27). Then, the following assertion holds:

(i) if $\omega_{n} \rightarrow 0$ as $n \rightarrow \infty$, then $\left\|x_{n+1}-x_{n}\right\| \rightarrow 0$.

If, in addition, $\sum_{k=0}^{\infty} \omega_{n}=\infty$, then

(ii) there exists a weak accumulation point $\tilde{x}$ of $\left\{x_{n}\right\}$;

(iii) all weak accumulation points of $\left\{x_{n}\right\}$ belong to $M$;

(iv) if $M$ is a singleton, that is, $M=\{\tilde{x}\}$, then $\left\{x_{n}\right\}$ converges weakly to $\tilde{x}$;

(v) if $J$ is weakly sequentially continuous on a bounded set containing $\left\{x_{n}\right\}$, then $\left\{x_{n}\right\}$ weakly converges to a point $\tilde{x} \in M$.

We omitted in this corollary the requirement that the sequence $\left\{\left\|F\left(x_{n}\right)\right\|\right\}$ have a limit because this limit always exists in this case by the estimate

$$
\left\|x_{n+1}-A x_{n+1}\right\| \leq\left\|x_{n}-A x_{n}\right\|
$$

Indeed, by (4.27),

$$
\begin{aligned}
\left\|x_{n+1}-A x_{n+1}\right\| & \leq\left\|\left(1-\omega_{n}\right) x_{n}-\omega_{n} A x_{n}-A x_{n+1}\right\| \\
& \leq\left(1-\omega_{n}\right)\left\|x_{n}-A x_{n}\right\|+\left\|A x_{n+1}-A x_{n}\right\| \\
& \leq\left(1-\omega_{n}\right)\left\|x_{n}-A x_{n}\right\|+\left\|x_{n+1}-x_{n}\right\| \\
& \leq\left(1-\omega_{n}\right)\left\|x_{n}-A x_{n}\right\|+\omega_{n}\left\|x_{n}-A x_{n}\right\| \\
& \leq\left\|x_{n}-A x_{n}\right\| .
\end{aligned}
$$

Now we introduce property $(\mathrm{P})$ : there exists a differentiable positive function $\tilde{\delta}_{B}(\varepsilon):[0,2] \rightarrow(0, \infty)$ such that $\delta_{B}(\varepsilon) \geq c \tilde{\delta}_{B}(\varepsilon), c>0$, and $\left|\tilde{\delta}_{B}^{\prime}(\varepsilon)\right| \leq C$. For example, the Lebesgue spaces $l^{p}, L^{p}$, and the Sobolev spaces $W^{m}, p, 1<p<\infty$, have this property.

THEOREM 4.6. Suppose that $B$ is a uniformly convex and uniformly smooth Banach space, $A: G \subset B \rightarrow B$ is a nonexpansive operator, $G$ is a closed convex subset of $B$, 
and the fixed point set $M$ of $A$ is not empty. Let $\left\{x_{n}\right\}$ be any sequence of iterates generated by the algorithm (3.1). Then, the following claims hold:

(i) if $\omega_{n} \rightarrow 0$ as $n \rightarrow \infty$, then $\left\|x_{n+1}-x_{n}\right\| \rightarrow 0$;

(ii) if, in addition, $B$ has property $(P), \sum_{n=0}^{\infty} \omega_{n}=\infty$, and $\sum_{n=0}^{\infty} \rho_{B}\left(\omega_{n}\right)<\infty$, then the statements (iii), (iv), ( $v$ ), and (vi) of Theorem 4.2 hold.

Proof. As before, the sequence $\left\{x_{n}\right\}$ is bounded, say by $R$, and the sequence $\left\{\left\|x_{n}-x^{*}\right\|\right\}$ has a limit. Therefore, using property (P), we obtain from (4.22) the following inequality:

$$
\begin{aligned}
& \left\|x_{n+1}-x^{*}\right\|^{2} \\
& \quad \leq\left\|x_{n}-x^{*}\right\|^{2}-(2 L)^{-1} c \bar{R}^{2} \omega_{n} \tilde{\delta}_{B}\left((2 \bar{R})^{-1}\left\|x_{n}-A x_{n}\right\|\right)+2^{-1} L \bar{R}^{2} \rho_{B}\left(8 \omega_{n}\right),
\end{aligned}
$$

where $\bar{R}=2\left(R+\left\|x^{*}\right\|\right)$ and $x^{*} \in M$. Since $\tilde{\delta}_{B}(\varepsilon)$ is differentiable, we can deduce for $\beta_{n}=\tilde{\delta}_{B}\left((2 \bar{R})^{-1}\left\|F x_{n}\right\|\right)$, the estimate

$$
\begin{aligned}
\left|\beta_{n+1}-\beta_{n}\right| & \leq\left|\tilde{\delta}_{B}^{\prime}(\xi)\right|||\left|F x_{n+1}\|-\| F x_{n} \|\right| \\
& \leq C(2 \bar{R})^{-1}|| F x_{n+1}-F x_{n}\left\|\leq 2 C(2 \bar{R})^{-1}\right\| x_{n+1}-x_{n} \|,
\end{aligned}
$$

where $\xi \in(0,2)$. Applying (4.21), we get

$$
\left|\beta_{n+1}-\beta_{n}\right| \leq C \bar{R}^{-1} \omega_{n}|| x_{n}-A x_{n}|| \leq C_{1} \omega_{n}
$$

By Lemma 2.3, we conclude that

$$
\beta_{n}=\tilde{\delta}_{B}\left((2 \bar{R})^{-1}\left\|F\left(x_{n}\right)\right\|\right) \longrightarrow 0 \quad \text { as } n \longrightarrow \infty
$$

Hence, (4.26) is valid. The rest of the proof follows the pattern of the proof of Theorem 4.2.

Remark 4.7. Different arguments (based on the proposition in [15]) show that in Theorem 4.4, Corollary 4.5, and Theorem 4.6, statement (vi) of Theorem 4.2 holds even if $J$ is not assumed to be weakly sequentially continuous.

Now we turn to a stability theorem for the method (4.1) with respect to perturbations of the set $G$. Consider the algorithm

$$
\begin{gathered}
0=\lambda_{n} F\left(Q_{G_{n+1}}\left(y_{n}\right)\right)+y_{n}-w_{n}, \\
w_{n+1}=Q_{G_{n+1}}\left(y_{n}\right), \quad w_{0} \in G_{0},
\end{gathered}
$$

where $\bar{\lambda} \geq \lambda_{n}>0, \sum_{0}^{\infty} \lambda_{n}=\infty$ and $\mathscr{H}\left(G_{n}, G\right) \leq \sigma_{n}$. 


\section{Iterative methods}

THeorem 4.8. Suppose that $B$ is a uniformly convex and uniformly smooth Banach space, $A: D(A) \subset B \rightarrow B$ is a nonexpansive operator, $G \subset D(A)$ and $G_{n} \subset D(A)$, $n=0,1, \ldots$, are closed convex subsets of $B$, and the fixed point set $M$ of $A$ is not empty. Let $\left\{\sigma_{n}\right\}$ be a sequence of positive numbers such that $\sum_{0}^{\infty} h_{B}\left(\sigma_{n}\right)<\infty$. If the iterative sequence $\left\{w_{n}\right\}$ generated by (4.34) is bounded, say by $R$ and $B$ has property $(P)$, then the conclusions (iii), (iv), (v), and (vi) of Theorem 4.2 are valid for $\left\{w_{n}\right\}$.

Proof. Once again, consider (4.6) with $x_{n}=w_{n}, y=y_{n}$ and an arbitrary $x \in G$ :

$$
\begin{aligned}
\left\|w_{n+1}-x\right\|^{2} \leq & \left\|w_{n}-x\right\|^{2}+2\left\langle w_{n+1}-w_{n}, J\left(w_{n+1}-x\right)\right\rangle \\
= & \left\|w_{n}-x\right\|^{2}+2\left\langle w_{n+1}-y_{n}, J\left(w_{n+1}-x\right)\right\rangle \\
& +2\left\langle y_{n}-w_{n}, J\left(w_{n+1}-x\right)\right\rangle .
\end{aligned}
$$

Since $\mathcal{H}\left(G_{n}, G\right) \leq \sigma_{n}$, there exists $u_{n+1} \in G_{n+1}$ such that $\left\|u_{n+1}-x\right\| \leq \sigma_{n+1}$ for all $n \geq 0$. Now we use Proposition 1.4 for $w_{n+1}=Q_{G_{n+1}} y_{n}$ and obtain

$$
\left\langle w_{n+1}-y_{n}, J\left(w_{n+1}-u_{n+1}\right)\right\rangle \leq 0 \text {. }
$$

Hence,

$$
\begin{aligned}
\left\langle w_{n+1}-y_{n}, J\left(w_{n+1}-x\right)\right\rangle= & \left\langle w_{n+1}-y_{n}, J\left(w_{n+1}-u_{n+1}\right)\right\rangle \\
& +\left\langle w_{n+1}-y_{n}, J\left(w_{n+1}-x\right)-J\left(w_{n+1}-u_{n+1}\right)\right\rangle \\
\leq & \left\langle u_{n+1}-y_{n}, J\left(w_{n+1}-x\right)-J\left(w_{n+1}-u_{n+1}\right)\right\rangle \\
\leq & \left\|u_{n+1}-y_{n}\right\|\left\|J\left(w_{n+1}-x\right)-J\left(w_{n+1}-u_{n+1}\right)\right\|_{*} .
\end{aligned}
$$

By (4.34) and the boundedness of $\left\{w_{n}\right\}$, there exist constants $C_{1}>0$ and $C_{2}>$ 0 such that

$$
\begin{aligned}
\left\|w_{n+1}-y_{n}\right\| & \leq\left\|w_{n+1}-w_{n}\right\|+\left\|w_{n}-y_{n}\right\| \\
& \leq\left\|w_{n+1}-w_{n}\right\|+\lambda_{n}\left\|F\left(w_{n+1}\right)\right\| \\
& \leq C_{1}+C_{2} \lambda_{n} .
\end{aligned}
$$

By (1.13), there exist constants $C_{3}>0$ and $C_{4}>0$ such that

$$
\begin{aligned}
\left\|J\left(w_{n+1}-x\right)-J\left(w_{n+1}-u_{n+1}\right)\right\|_{*} & \leq C_{3} h_{B}\left(C_{4}\left\|u_{n+1}-x\right\|\right) \\
& \leq C_{3} h_{B}\left(C_{4} \sigma_{n+1}\right) .
\end{aligned}
$$


By (4.35) and property $(\mathrm{P})$, this implies the inequality

$$
\begin{aligned}
\| w_{n+1} & -x^{*}\left\|^{2}-\right\| w_{n}-x^{*} \|^{2} \\
\leq & -2 \lambda_{n}\left\langle F w_{n+1}, J\left(w_{n+1}-x^{*}\right)\right\rangle+\left(C_{1}+C_{2} \lambda_{n}\right) C_{3} h_{B}\left(C_{4} \sigma_{n+1}\right) \\
\leq & -(2 L)^{-1} c \bar{R}^{2} \lambda_{n} \tilde{\delta}_{B}\left((2 \bar{R})^{-1}\left\|w_{n}-A w_{n}\right\|\right) \\
& +\left(C_{1}+C_{2} \lambda_{n}\right) C_{3} h_{B}\left(C_{4} \sigma_{n+1}\right)
\end{aligned}
$$

where $\bar{R}=2\left(R+\left\|x^{*}\right\|\right)$ and $x^{*} \in M$. Lemma 2.3 and the properties of $\delta_{B}(\varepsilon)$ imply (4.33) and (4.26). Once again, the rest of the proof follows the pattern of the proof of Theorem 4.2 .

In conclusion, we consider the stability of the following descent-like approximations with respect to perturbations of the set $G$ :

$$
v_{n+1}=Q_{G_{n+1}}\left(v_{n}-\omega_{n}\left(v_{n}-A v_{n}\right)\right), \quad n=0,1,2, \ldots
$$

where $Q_{G}: B \rightarrow G$ is the sunny nonexpansive retraction of $B$ onto $G$ and $A: G \rightarrow$ $B$ is a nonexpansive mapping.

THeorem 4.9. Suppose that $B$ is a uniformly convex and uniformly smooth Banach space, $A: D(A) \subset B \rightarrow B$ is a nonexpansive operator, $G \subset D(A)$ and $G_{n} \subset D(A)$, $n=0,1, \ldots$, are closed convex subsets such that the Hausdorff distance $\mathcal{H}\left(G_{n}, G\right) \leq$ $\sigma_{n}$, and the fixed point set $M$ of $A$ is not empty. Let $\left\{\sigma_{n}\right\}$ be a sequence of positive numbers such that $\sum_{n=0}^{\infty} h_{B}^{1 / 2}\left(\sigma_{n}\right)<\infty$. If the iterative sequence generated by (4.41) is bounded, say by $R$, then

(1) if $\omega_{n} \rightarrow 0$ as $n \rightarrow \infty$, then $\left\|v_{n+1}-v_{n}\right\| \rightarrow 0$;

(2) if, in addition, the space $B$ has property $(P), \sum_{n=0}^{\infty} \omega_{n}=\infty, \omega_{n} \leq \omega$, and $\sum_{n=0}^{\infty} \rho_{B}\left(\omega_{n}\right)<\infty$, then the conclusions (iii), (iv), ( $v$ ), and (vi) of Theorem 4.2 hold.

Proof. It follows from (4.41) that

$$
\begin{aligned}
\left\|v_{n+1}-v_{n}\right\| & =\left\|Q_{G_{n+1}}\left(v_{n}-\omega_{n}\left(v_{n}-A v_{n}\right)\right)-Q_{G_{n+1}} v_{n}\right\|+\left\|Q_{G_{n+1}} v_{n}-Q_{G_{n}} v_{n}\right\| \\
& =Z_{1}+Z_{2} .
\end{aligned}
$$

The operator $Q$ is a nonexpansive retraction, therefore,

$$
Z_{1}=\left\|Q_{G_{n+1}}\left(v_{n}-\omega_{n}\left(v_{n}-A v_{n}\right)\right)-Q_{G_{n+1}} v_{n}\right\| \leq \omega_{n}\left\|v_{n}-A v_{n}\right\| .
$$


214 Iterative methods

Since $\left\|v_{n}-A v_{n}\right\|$ is bounded, $Z_{1} \rightarrow 0$ as $\omega_{n} \rightarrow 0$. Furthermore, we can estimate $Z_{2}$ by Lemma 3.4. Indeed, there exist constants $C_{1}>0$ and $C_{2}>0$ such that

$$
Z_{2}=\left\|Q_{G_{n+1}} v_{n}-Q_{G_{n}} v_{n}\right\| \leq C_{1} h_{B}^{1 / 2}\left(C_{2}\left(\sigma_{n+1}+\sigma_{n}\right)\right)
$$

because $\left\{v_{n}\right\}$ is bounded and

$$
\mathscr{H}\left(G_{n+1}, G_{n}\right) \leq \mathscr{H}\left(G_{n+1}, G\right)+\mathscr{H}\left(G_{n}, G\right) \leq \sigma_{n+1}+\sigma_{n} .
$$

It is clear that $Z_{2} \rightarrow 0$ as $\sigma_{n} \rightarrow 0$. Thus claim (1) is true.

Next we note that for any $x^{*} \in M$,

$$
\left\|v_{n+1}-x^{*}\right\| \leq\left\|v_{n+1}-Q_{G_{n+1}} x^{*}\right\|+\left\|Q_{G_{n+1}} x^{*}-Q_{G} x^{*}\right\| .
$$

By Lemma 3.4, there exist constants $C_{3}>0$ and $C_{4}>0$ such that

$$
\left\|Q_{G_{n+1}} x^{*}-Q_{G} x^{*}\right\| \leq C_{3} h_{B}^{1 / 2}\left(C_{4} \sigma_{n+1}\right) .
$$

Estimating the first term on the right-hand side of (4.46), we have

$$
\left\|v_{n+1}-Q_{G_{n+1}} x^{*}\right\| \leq\left\|Q_{G_{n+1}} \phi_{n}-Q_{G_{n+1}} x^{*}\right\| \leq\left\|\phi_{n}-x^{*}\right\|
$$

where $\phi_{n}=v_{n}-\omega_{n}\left(v_{n}-A v_{n}\right)$. Since $\left\{\phi_{n}\right\}$ is bounded, then there exists a constant $C_{5}>0$ such that

$$
\left\|v_{n+1}-Q_{G_{n+1}} x^{*}\right\| \leq C_{5} .
$$

Thus,

$$
\left\|v_{n+1}-x^{*}\right\|^{2} \leq\left\|v_{n+1}-Q_{G_{n+1}} x^{*}\right\|^{2}+2 C_{5} C_{3} h_{B}^{1 / 2}\left(C_{4} \sigma_{n+1}\right)+C_{3}^{2} h_{B}\left(C_{4} \sigma_{n+1}\right) .
$$

It is clear that

$$
\left\|v_{n+1}-Q_{G_{n+1}} x^{*}\right\|^{2} \leq\left\|\phi_{n}-x^{*}\right\|^{2}
$$

Similarly to (4.22), we see that

$$
\begin{aligned}
\| \phi_{n}- & x^{*} \|^{2} \\
& \leq\left\|v_{n}-x^{*}\right\|^{2}-(2 L)^{-1} c \bar{R}^{2} \omega_{n} \bar{\delta}_{B}\left((2 \bar{R})^{-1}\left\|v_{n}-A v_{n}\right\|\right)+2^{-1} L \bar{R}^{2} \rho_{B}\left(8 \omega_{n}\right),
\end{aligned}
$$


where $\left\|v_{n}\right\| \leq R$ and $\bar{R}=2(1+2 \omega)\left(R+\left\|x^{*}\right\|\right)$. Finally, we obtain the following inequality:

$$
\begin{aligned}
\left\|v_{n+1}-x^{*}\right\|^{2} \leq & \left\|v_{n}-x^{*}\right\|^{2}-(2 L)^{-1} c \bar{R}^{2} \omega_{n} \bar{\delta}_{B}\left((2 \bar{R})^{-1}\left\|F v_{n}\right\|\right) \\
& +2^{-1} L \bar{R}^{2} \rho_{B}\left(8 \omega_{n}\right)+2 C_{5} C_{3} h_{B}^{1 / 2}\left(C_{4} \sigma_{n+1}\right)+C_{3}^{2} h_{B}\left(C_{4} \sigma_{n+1}\right) .
\end{aligned}
$$

If $\sum_{n=0}^{\infty} \omega_{n}=\infty, \sum_{n=0}^{\infty} h_{B}^{1 / 2}\left(\sigma_{n}\right)<\infty$ and $\sum_{n=0}^{\infty} \rho_{B}\left(\omega_{n}\right)<\infty$, then $\left\|F v_{n}\right\| \rightarrow 0$. This leads to the conclusions (iii), (iv), (v), and (vi) of Theorem 4.2.

Remark 4.10. Strong convergence of approximants to fixed points of nonexpansive, nonself-mappings can be obtained by applying some regularization procedures (cf. $[14,18])$.

\section{Acknowledgments}

The first author was supported in part by the KAMEA Program of the Ministry of Absorption. The second author was partially supported by the Fund for the Promotion of Research at the Technion and by the Technion VPR Fund. The third author was supported in part by a grant from the National Science Council.

\section{References}

[1] Ya. I. Alber, New results in fixed point theory, preprint, 1999.

[2] - Generalized projection operators in Banach spaces: properties and applications, Functional-Differential Equations, Functional Differential Equations, Israel Seminar, vol. 1, Coll. Judea Samaria, Ariel, 1993, pp. 1-21.

[3] _ Metric and generalized projection operators in Banach spaces: properties and applications, Theory and Applications of Nonlinear Operators of Accretive and Monotone Type (A. Kartsatos, ed.), Lecture Notes in Pure and Applied Mathematics, vol. 178, Dekker, New York, 1996, pp. 15-50.

[4] Ya. I. Alber and S. Guerre-Delabriere, Principle of weakly contractive maps in Hilbert spaces, New Results in Operator Theory and Its Applications, Operator Theory: Advances and Applications, vol. 98, Birkhäuser, Basel, 1997, pp. 7-22.

[5]_, On the projection methods for fixed point problems, Analysis (Munich) 21 (2001), no. 1, 17-39.

[6] Ya. I. Alber, S. Guerre-Delabriere, and L. Zelenko, The principle of weakly contractive mappings in metric spaces, Comm. Appl. Nonlinear Anal. 5 (1998), no. 1, 45-68.

[7] Ya. I. Alber and A. N. Iusem, Extension of subgradient techniques for nonsmooth optimization in Banach spaces, Set-Valued Anal. 9 (2001), no. 4, 315-335.

[8] Ya. I. Alber and S. Reich, An iterative method for solving a class of nonlinear operator equations in Banach spaces, Panamer. Math. J. 4 (1994), no. 2, 39-54.

[9] R. E. Bruck Jr., Nonexpansive projections on subsets of Banach spaces, Pacific J. Math. 47 (1973), 341-355.

[10] T. Figiel, On the moduli of convexity and smoothness, Studia Math. 56 (1976), no. 2, 121-155. 


\section{Iterative methods}

[11] K. Goebel and S. Reich, Uniform Convexity, Hyperbolic Geometry, and Nonexpansive Mappings, Monographs and Textbooks in Pure and Applied Mathematics, vol. 83, Marcel Dekker, New York, 1984.

[12] J. Lindenstrauss and L. Tzafriri, Classical Banach Spaces. II, Ergebnisse der Mathematik und ihrer Grenzgebiete, vol. 97, Springer-Verlag, Berlin, 1979.

[13] S. Reich, Asymptotic behavior of contractions in Banach spaces, J. Math. Anal. Appl. 44 (1973), 57-70.

[14] Extension problems for accretive sets in Banach spaces, J. Functional Analysis 26 (1977), no. 4, 378-395.

[15] Weak convergence theorems for nonexpansive mappings in Banach spaces, J. Math. Anal. Appl. 67 (1979), no. 2, 274-276.

[16] Product formulas, nonlinear semigroups, and accretive operators, J. Funct. Anal. 36 (1980), no. 2, 147-168.

[17] I. Şerb, Some estimates for the modulus of smoothness and convexity of a Banach space, Mathematica (Cluj) 34(57) (1992), no. 1, 61-70.

[18] W. Takahashi and G.-E. Kim, Strong convergence of approximants to fixed points of nonexpansive nonself-mappings in Banach spaces, Nonlinear Anal. 32 (1998), no. $3,447-454$.

Yakov Alber: Department of Mathematics, The Technion - Israel Institute of Technology, 32000 Haifa, Israel

E-mail address: alberya@tx.technion.ac.il

Simeon Reich: Department of Mathematics, The Technion - Israel Institute of Technology, 32000 Haifa, Israel

E-mail address: sreich@tx.technion.ac.il

Jen-Chih Yao: Department of Applied Mathematics, National Sun Yat-sen University, 804 Kaohsiung, Taiwan

E-mail address: yaojc@math.nsysu.edu.tw 


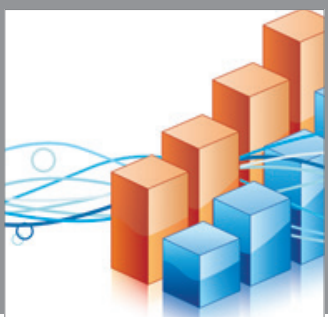

Advances in

Operations Research

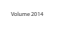

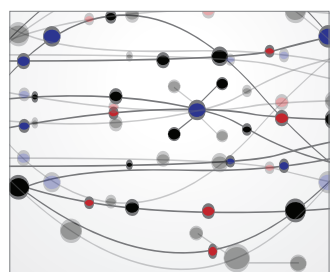

\section{The Scientific} World Journal
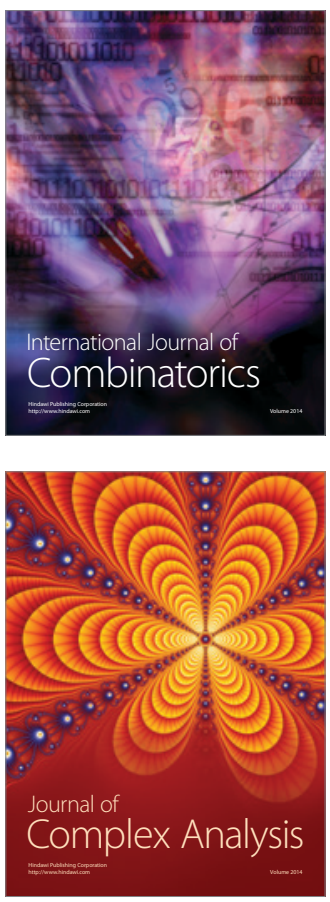

International Journal of

Mathematics and

Mathematical

Sciences
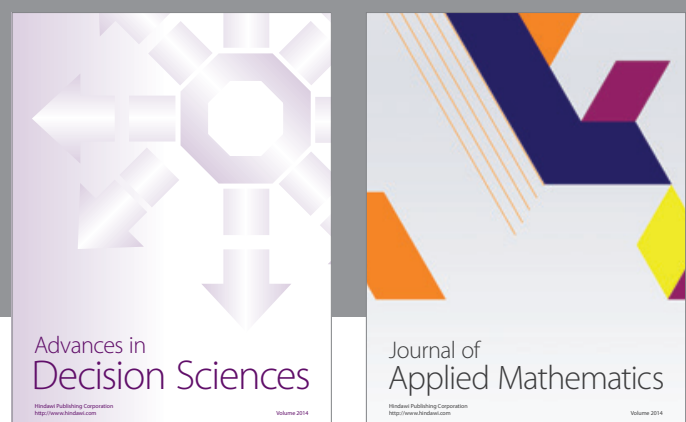

Journal of

Applied Mathematics
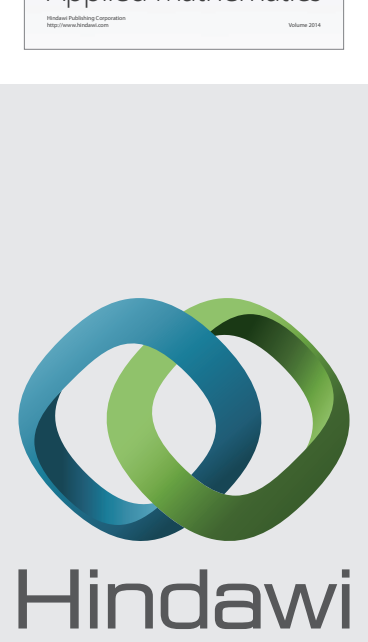

Submit your manuscripts at http://www.hindawi.com
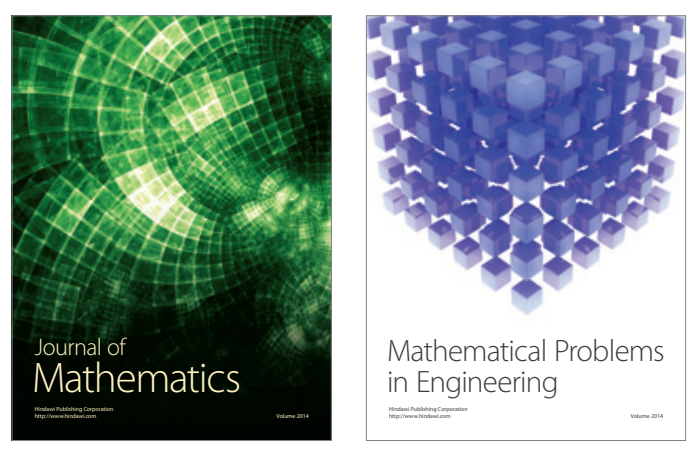

Mathematical Problems in Engineering
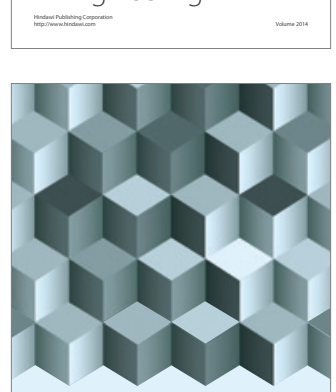

Journal of

Function Spaces
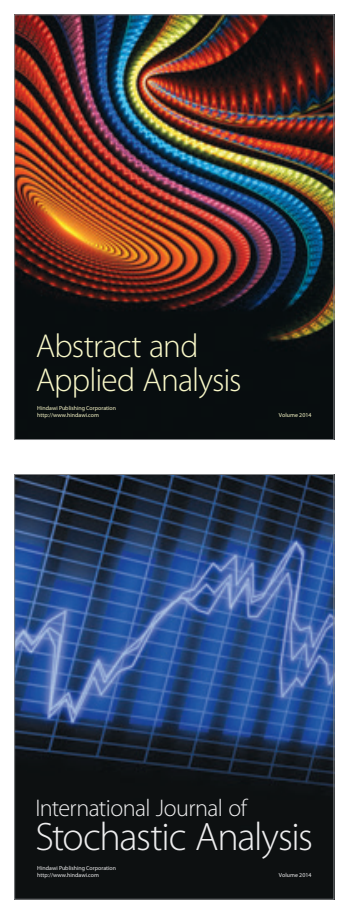

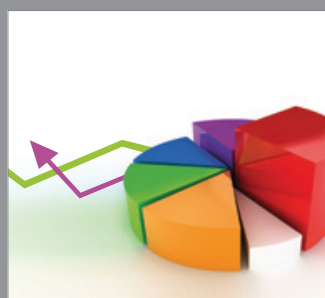

ournal of

Probability and Statistics

Promensencen
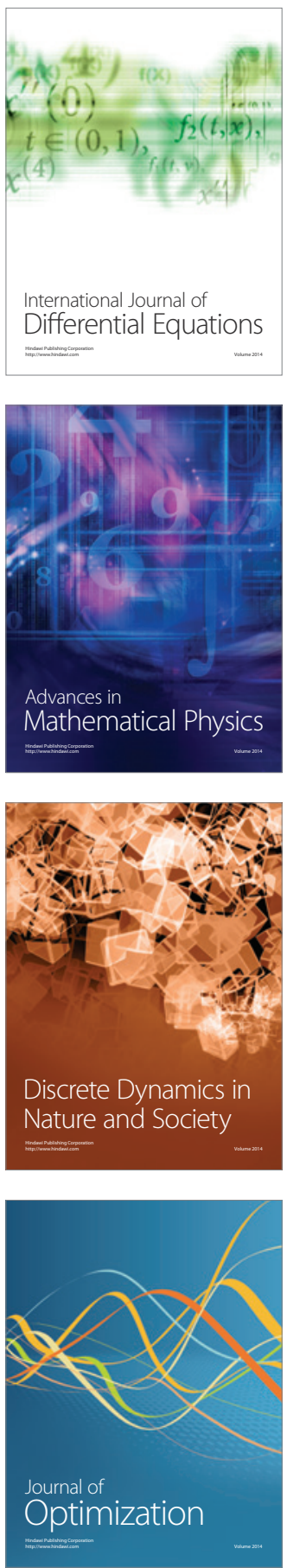